\title{
Bolivia's Fiscal Rules: \\ Dynamic Stochastic General Equilibrium Model Approach
}

\section{By}

\section{Daney D. Valdivia}

\author{
Marcelo A. Montenegro ${ }^{1}$
}

\begin{abstract}
Changes in fiscal revenues in Bolivia allow us to assess its impact on the fiscal budget and spending policy. Based on a Dynamic Stochastic General Equilibrium Model (DGSE) in line with the new macroeconomic vintage and using stylized facts for small open economy, we're looking for a simulation of fundamentals' responses or effects against different fiscal rules applied. In accordance with this we use two rules: first, where taxes adjust according to the debt level and government expenditures; and second, balanced budget where taxes adjust every time in order to maintain the equilibrium in budget. Our results show that after the fiscal shock hits the economy, the first fiscal rule has mayor stabilization effects on the price level than the second one, around $50 \%$.
\end{abstract}

\section{JEL: E32, E62}

Keywords: Government expenditure, fiscal rule, pass - through, rule - of - thumb bouseholds

1 Daney D. Valdivia, economist: daney.valdivia@economiayfinanzas.gov.bo, daneyvaldivia@yahoo.com,; and Marcelo A. Montenegro, Chief of a main directorate of Tributary Studies: mmontenegro@hacienda.gov.bo, montenegro mzx@yahoo.es

The authors are solely responsible for the opinions herein.

We thank Lilian Loayza for help with the edition and Rubén Aguilar with some seasonal adjustment series. 


\section{Introduction}

One of the central issues of Policy Makers is to assess the Fiscal Policy effects in the economy. Developing economies use this tool as one of the principal mechanism to push up aggregate demand and welfare. Additionally, Fiscal Policy can contribute to the economy growth or it may harm to the economy through fiscal budget disequilibrium.

Superavit in 2006 was positive for Bolivia, 4.6\%. What's more, fiscal income structure was benefit as a result of direct taxation to oil and positive evolution of commodity prices. Moreover, in the first half of 2007 Bolivia had a positive result, 4.2\%, and for the exercise ended on 2007, the superavit was $1.8 \%$. So, this positive environment induces increments in fiscal spending to look for social income redistribution.

Nonetheless, one of the Fiscal Policy's principal should be to assess the fiscal budget, its viability and sustainability through time in order to avoid future fiscal disequilibrium so as to not have negative effects in the economy.

The purpose of the paper is to review and analyze the fiscal expenditure effects of fiscal rules simulation on Bolivia's economy. But, Bolivia doesn't have any fiscal rule; then, different fiscal rule impositions or simulations will help us assess the performance of the fundamentals in the economy through the fiscal policy mechanism. Thus, we reach our objective using a dynamic stochastic general equilibrium (DSGE) model with the New Keynesian macroeconomic vintage for a small open economy (SOE) and applying different types of shocks.

Based on Galí et. al. (2007), the paper builds a Dynamic Stochastic General Equilibrium Model (DSGE) with the advances of New Keynesian Theory. It uses consumption heterogeneity (rule - of - thumb), market imperfection, and sticky prices and applies different types of fiscal rules. First, as in Galí et. al. (2007), taxes are endogenous and move in response to government expenditure and debt level. The second uses a balanced budget in every period where taxes react every period. 
In particular, we modified the principal benchmark in order to find more relations, which allow us to explain Bolivia's economy since it is a small dollarized open economy (SDOE). In order to simplify the external effects we use the Hybrid New Keynesian Phillips Curve. Based on Balakrishnan and López Salido, (2002) we modified the production function and its factor structure so as to put in and assess the pass - through to the economy.

At the same time, Monetary Policy in Bolivia doesn't have traditional instruments to shock the economy, like an interest rate rule (Taylor Rule). So, we use one that can be applied in a small open economy and allow us to assess its effects. Based on Schmidt - Hebbel and Tapia (2002) and Caputo et. al. (2006), we use a Taylor rule where the interest rate not only reacts to the inflation and output deviations, but also to interest rate lags and changes to nominal exchange rate.

We use DYNARE in order to solve the model, but first it must be log - linearized. Furthermore, parameters calibration is used for Bolivia's economy in order to simulate its behavior and contemporaneous ones common in literature that also can explain the behavior in other developing economies.

The two fiscal rules applied are compared with a model that doesn't consider a fiscal rule. Therefore, canonical models allow us to assess the true multiplier effect of fiscal shocks on fundamental macroeconomic variables for Bolivia.

A Fiscal shock produces an increase in total consumption explained by a positive increase in the rule - of - thumb households. However, a fiscal shock generates pressures on inflation, it increase through the cost channel; after that, interest rate increases against fiscal pressures on inflation restrained pressures on inflation.

Furthermore, the model structure allows us to assess the effects of the fiscal shock on the other variables. It produces nominal exchange rate depreciation and real exchange rate appreciation. On the other hand, risk premium and tax pressure increases. 
The paper is organized as follows: section 2, reviews literature about fiscal expenditure effects and other economies experience; section 3, develop the model methodology; section 4, describes data and calibration; section 5, shows fiscal shock effects under the two fiscal rules, and finally section 6 , concludes and give new future investigation guidelines

\section{Literature review}

There is no explicit evidence in Bolivia that tried to study the fiscal rules effects on the economy in the new macroeconomic vintage, called Newkeynesian. Then, empirical papers and investigation in this way are restricted to other economies.

\subsection{Foreign evidence}

The negative response of the consumption against an increase in government spending is insufficient. This result can be obtained in Ricardian RBC models or as in the neoclassical model predictions, Christiano and Eichenbaum (2002), and Fatás and Mihov (2001, FM).

Therefore most of the evidence is concentrated in VAR models. Blanchard and Perotti (2002, BP) and FM (2001) found that, against to neoclassical models, in response to a fiscal expenditure shock consumption increases, but in different degree. Besides, investment doesn't have a unique response: in the first case, investment falls in great magnitude; and, in the second one, investment increases insignificantly.

Using United States quarterly data, Galí et al (2007) show when an increase in government spending is significantly. Consequently, it produces a persistent increase in output and at the same time a persistent increase in consumption ${ }^{2}$. Then, working hours and real wage increases; and in the short run investment falls but in the medium it improves, but not significantly. What is more, deficit increases, too.

\footnotetext{
2 This output is explained because of the introductions of rule - of - thumb consumers in the canonical structure of the model
} 
Mountford y Uhlig (2004), Burnside et al (2003) find that in response to a fiscal shock, consumption response is weak and not significant.

In addition, Alesina and Ardagna (1998) show that during periods of fiscal consolidation the forecast of the neoclassical model is good; consequently, a fiscal spending reduction cause a positive variation in consumption and output.

In summary, the evidence in favor of negative comovement between output and consumption in response to a fiscal positive shock is not consistent with the neoclassical model.

\section{Model Methodology}

The model is based on Gali et. al. (2007), we model a small open economy (SOE) in order to introduce the Bolivia's economy characteristics.

\subsection{Households}

New Keynesian models with rule - of - thumb households, includes myopic or lack of credit, helps us to explain positive movements in total consumption against business cycle models with full ricardian consumers or neoclassical models. Rule - of - thumb households only consume the product of their work, they have fear to save (asset accumulation) and ignore intertemporal consumption. On the other hand, ricardian households or optimizers have assets and access to the capital market and receive benefits of the firms.

The coexistence of these two types of agents allows us to explain the positive movement of total consumption in response to a fiscal shock.

\subsubsection{Ricardian households}

They have a utility function subject to a budget constrain and response to their own characteristics. Following Galí et. al. (2007) we can introduce investment at last. 


$$
E_{0} \sum_{t=0}^{\infty} \beta^{t} U\left(C_{t}^{o}, N_{t}^{o}\right)
$$

According to Andrés and Domenéch (2005), and García and Restrepo (2007) the budget constrain can be:

$$
\begin{aligned}
P_{t}\left(\left(1+\tau_{t}^{c}\right) C_{t}^{o}+I_{t}^{o}\right)+ & R_{t}^{-1} B_{t+1}^{o}+S_{t}\left(\Phi\left(\frac{S_{t} B_{t}^{*}}{P_{t} Y_{t}}\right) R_{t}^{*}\right)^{-1} B_{t+1}^{o *}= \\
& P_{t}\left(1-\tau_{t}^{N}\right) W_{t} N_{t}^{o}+P_{t}\left(1-\tau_{t}^{K}\right) Z_{t} K_{t}^{o}+B_{t}^{o}+S_{t} B_{t}^{o *}+\left(1-\tau_{t}^{D}\right) D_{t}^{o}-P_{t} T_{t}^{o}
\end{aligned}
$$

Capital law of motion with adjustment cost is:

$$
K_{t+1}^{o}=(1-\delta) K_{t}^{o}+\phi\left(\frac{I_{t}^{o}}{K_{t}^{o}}\right) K_{t}^{o}
$$

Where tax structure: $\tau_{t}^{c}, \tau_{t}^{N}, \tau_{t}^{K}, \tau_{t}^{D}$, are tax rates to consumption, labor income, capital return and dividends. Domestic and foreign debt, or assets, are $B_{t}^{o}, B_{t}^{o^{*}}$. Nominal Exchange rate is $\mathrm{S}_{\mathrm{t}}$ and country risk premium is $\Phi\left(\frac{S_{t} B_{t}^{*}}{P_{t} Y_{t}}\right)$. Dividends are $D_{t}^{o}$, and the domestic and the foreign interest rate are $R_{t}, R_{t}^{*}$. Real price of factors are $\mathrm{W}_{\mathrm{t}}, \mathrm{Z}_{\mathrm{t}}$. Capital and labor are $N_{t}^{o}, K_{t}^{o}$ and $\mathrm{P}_{\mathrm{t}}$ is the price level. Finally, $T_{t}^{o}$ is defined as lump sum taxes (or transfers if it is negative) paid by Ricardian consumers.

Furthermore, capital law of motion must be $\phi^{\prime}()>0, \phi^{\prime \prime}() \leq 0$ with $\phi^{\prime}(\delta)=1$, and adjustment cost function in steady state are equal to capital depreciation rate, $\phi(\delta)=\delta$.

The utility function takes the form:

$$
U(\bullet)=\frac{v_{t}^{c} C_{t}^{1-\sigma}}{1-\sigma}-\frac{v_{t}^{N} N_{t}^{1+\varphi}}{1+\varphi}
$$


Where $v_{t}^{c}, v_{t}^{N}$ are idiosyncratic shocks of preference that hits consumption and labor. The taxation effect on Ricardian households can be seen in the Euler equation that is shocked by preference shocks.

Optimal conditions are:

$$
\begin{aligned}
& 1=\beta E_{t}\left(\frac{\lambda_{t+1}}{\lambda_{t}}\left(R_{t} \frac{P_{t}}{P_{t+1}}\right)\right) \\
& 1=\beta E_{t}\left(\frac{\lambda_{t+1}}{\lambda_{t}}\left(\frac{S_{t+1}}{S_{t}}\left(\Phi\left(\frac{S_{t} B_{t}^{*}}{P_{t} Y_{t}}\right) R_{t}^{*}\right) \frac{P_{t}}{P_{t+1}}\right)\right)
\end{aligned}
$$

The Euler equation is:

$$
C_{t}^{o^{-\sigma}}=\beta E_{t}\left(C_{t+1}^{o^{-\sigma}} R_{t}\left(\frac{P_{t}}{P_{t+1}}\right)\left(\frac{1+\tau_{t}^{c}}{1+\tau_{t+1}^{c}}\right)\left(\frac{v_{t+1}^{c}}{v_{t}^{c}}\right)\right)
$$

Capital shadow price, Tobin's Q, is given by:

$$
\begin{gathered}
Q_{t}=\frac{1}{\phi^{\prime}(\bullet)} \\
Q_{t}=\beta\left(\frac{\lambda_{t+1}}{\lambda_{t}}\left(Z_{t+1}\left(1-\tau_{t+1}^{K}\right)+Q_{t+1}\left((1-\delta)+\phi\left(\frac{I_{t+1}^{o}}{K_{t+1}^{o}}\right)-\phi^{\prime}\left(\frac{I_{t+1}^{o}}{K_{t+1}^{o}}\right) \frac{I_{t+1}^{o}}{K_{t+1}^{o}}\right)\right)\right)
\end{gathered}
$$

Moreover, we have two options related to the labor market structure: first, a competitive labor market where each household chooses a labor supply given the market wage and; second, wages can be fixed by unions ${ }^{3}$. Then, in the last case, wages can be determined by households.

Therefore, labor supply is influenced not only by taxes on consumption and work, but also is affected by preference shocks.

\footnotetext{
${ }^{3}$ Bénassy (2002) ch 5.
} 


$$
N_{t}^{o^{\varphi}} C_{t}^{o^{\sigma}}=W_{t} \frac{\left(1-\tau_{t}^{N}\right)}{\left(1+\tau_{t}^{c}\right)} \frac{v_{t}^{c}}{v_{t}^{N}}
$$

\subsubsection{Rule - of - Thumb households}

This type of households only receives income labor for their work. Therefore, they consume all of their labor income and don't save anything. Additionally, they don't have access to the capital markets.

They have a utility function:

$$
U\left(C_{t}^{r}, N_{t}^{r}\right)
$$

Subject to:

$$
P_{t}\left(1+\tau_{t}^{c}\right) C_{t}^{r}=P_{t}\left(1-\tau_{t}^{N}\right) W_{t} N_{t}^{r}
$$

\subsection{Demand goods}

In order to find good market equilibrium we need to differentiate domestic and foreign consumption. Following Gali and Monacelli (2005), consumption takes a CES form.

$$
C_{t}=\left((1-\alpha) \frac{1}{\eta^{c}}\left(C_{H, t}\right) \frac{\eta^{c}-1}{\eta^{c}}+\alpha_{\eta^{c}}^{\frac{1}{c}}\left(C_{F, t}\right)^{\frac{\eta^{c}-1}{\eta^{c}}}\right)^{\frac{\eta^{c}}{\eta^{c}-1}}
$$

Where $C_{H, t}, C_{F, t}$ are consumption of domestic and foreign goods ${ }^{4}$ and take a CES form. The Dixit - Stiglitz aggregators of imported and domestic goods are:

$$
C_{H, t}=(1-\alpha)\left(\frac{P_{H, t}}{P_{t}}\right)^{-\eta^{c}} C_{t}
$$

\footnotetext{
4 We didn't take into account imported goods because we use the New Keynesian Phillips Curve, and put imported goods in the production function and it takes the CES form. So, effects of imported prices affect directly to the NKPC.
} 


$$
C_{F, t}=\alpha\left(\frac{P_{F, t}}{P_{t}}\right)^{-\eta^{c}} C_{t}
$$

and it is supposed that the aggregate price level is given by:

$$
P_{t}=\left((1-\alpha)\left(P_{H, t}\right)^{1-\eta^{c}}+\alpha\left(P_{F, t}\right)^{1-\eta^{c}}\right)^{\frac{1}{1-\eta^{c}}}
$$

So, if $P_{F, t}=P_{H, t}, \alpha$ is the proportion for domestic goods given the imported goods. $\alpha$ is the natural open index, too.

\subsection{Aggregation}

Aggregation is as follows: Total consumption is the sum of Ricardian households and rule - of

- thumb. The total number of hours worked is the same as total consumption and $\lambda$ is the share of rule - of - thumb.

$$
\begin{aligned}
& C_{t}=\lambda C_{t}^{r}+(1-\lambda) C_{t}^{o} \\
& N_{t}=\lambda N_{t}^{r}+(1-\lambda) N_{t}^{o}
\end{aligned}
$$

Since only Ricardian consumers have access to the capital market, investment and capital stock market are given by:

$$
\begin{aligned}
& I_{t}=(1-\lambda) I_{t}^{o} \\
& K_{t}=(1-\lambda) K_{t}^{o}
\end{aligned}
$$

Domestic and foreign assets, including fiscal debt $B_{t}^{G^{*}}$ are given by:

$$
B_{t}=(1-\lambda) B_{t}^{o}
$$




$$
B_{t}^{*}=B_{t}^{G^{*}}+(1-\lambda) B_{t}^{o^{*}}
$$

\subsection{Firms}

There exists a continuum set of competitive monopolistic firms. All of them produce only intermediate goods; but production factors are competitive. In particular, final goods are produced by constant return technology (CES production function).

$$
Y_{t}=\left(\int_{0}^{1} Y_{t}(j)^{\frac{\varepsilon_{p}-1}{\varepsilon_{p}}} d j\right)^{\frac{\varepsilon_{p}}{\varepsilon_{p}-1}}
$$

$Y_{t}(j)$ Is the quantity of intermediate goods used as input? So, intermediate goods demand is given by Dixit - Stiglitz aggregator:

$$
Y_{t}(j)=\left(\frac{P_{t}(j)}{P_{t}}\right)^{-\varepsilon_{p}} Y_{t}
$$

And prices are given by:

$$
P_{t}=\left(\int_{0}^{1} P_{t}(j)^{1-\varepsilon_{p}} d j\right)^{\frac{1}{1-\varepsilon_{p}}}
$$

\subsubsection{Intermediate Goods}

We assume a continuum set of monopolistic firms. In order to put the pass- through in the price equation, HNKPC, we use imported price goods as input. Our production function takes a CES form with $\mathrm{M}$ and $\mathrm{N}$ as inputs.

$$
Y_{t}(j)=A_{t}\left(\alpha_{M} M(j)_{t}^{\frac{\sigma_{s}-1}{\sigma_{s}}}+\alpha_{N} N(j)_{t}^{\frac{\sigma_{s}-1}{\sigma_{s}}}\right)^{\frac{\sigma_{s}}{\sigma_{s}-1}}
$$


$A_{t}$ is the technology and technology shock acts through this, and $\sigma_{s}$ is the elasticity of substitution between imported goods and work. Both of them are greater than zero. Intermediate imported goods are $M(j)_{t}{ }^{5}$.

Given that the real price of factors $P_{t}^{M}$ and $W_{t}$, the equilibrium through a minimization cost is:

$$
\frac{W_{t}}{P_{t}^{M}}=\frac{\alpha}{1-\alpha}\left(\frac{M(j)_{t}}{N(j)_{t}}\right)^{\frac{1}{\sigma_{s}}}
$$

Marginal cost is given by:

$$
M C=(1-\alpha)^{\frac{2 \sigma_{s}-1}{\sigma_{s}}}\left(P_{t}^{M}\right)^{1-\sigma_{s}}+(\alpha)^{\frac{2 \sigma_{s}-1}{\sigma_{s}}}\left(W_{t}\right)^{1-\sigma_{s}}
$$

\subsubsection{Price setting}

Following Calvo (1983), (1- $\theta)$ is the fraction of firms that reset prices optimally, believing that the price chosen will be optimal for the periods ahead. While a fraction $\theta$ keep their prices unchanged. Based on Galí and Gertler (1999), we can put in the optimal price a fraction of firms that reset their prices forward - looking, (1- $\omega)$. At the same time, a fraction $\omega$ set prices backward - looking. This set of firms reset their prices based on the optimal price and inflation in $\mathrm{t}-1$.

$$
\operatorname{Max} \sum_{k=0}^{\infty} \theta^{k} E_{t}\left\{\Lambda_{t, t+k}\left(P_{t}^{f^{*}}(j) Y_{t+k}(j)-\Psi_{t+k}\left(Y_{t+k}(j)\right)\right)\right\}
$$

Subject to

$$
Y_{t+k}(j)=\left(\frac{P_{t}^{f^{*}}(j)}{P_{t+k}}\right)^{-\varepsilon_{p}} Y_{t+k}
$$

\footnotetext{
${ }^{5}$ Intermediate firms' aggregation also takes a CES form.
} 
Cost function is $\Psi_{t+k}\left(Y_{t+k}(j)\right)$ and $P_{t}^{f^{*}}$ must satisfy the first order condition:

$$
\sum_{k=0}^{\infty} \theta^{k} E_{t}\left\{\Lambda_{t, t+k} Y_{t+k}\left(P_{t}^{f^{*}}(j)-\mu \varphi_{t+k}(j)\right)\right\}=0
$$

Where $\mu=\frac{\varepsilon_{p}}{\varepsilon_{p}-1}$ is the gross mark - up when inflation is zero in steady state and nominal marginal cost is given by $\varphi_{t+k}(\bullet)=\Psi_{t+k}^{\prime}(\bullet)$. Furthermore, factor discount is given by:

$$
\Lambda_{t, t+k}=\beta^{k} E_{t}\left(\frac{C_{t+1}^{o^{-}}}{C_{t}^{o^{-}}}\left(\frac{P_{t}}{P_{t+1}}\right)\left(\frac{1+\tau_{t}^{c}}{1+\tau_{t+1}^{c}}\right)\left(\frac{v_{t+1}^{c}}{v_{t}^{c}}\right)\right)
$$

In steady state we can get $\Lambda_{t, t+k}=\beta^{k}$. Moreover, to complete the dynamic price we must use the following equation.

$$
\begin{aligned}
& P_{t}=\theta P_{t-1}+(1-\theta) P_{t}^{*} \\
& P_{t}^{*}=(1-\omega) P_{t}^{f^{*}}+\omega P_{t}^{b^{*}} \\
& P_{t}^{b^{*}}=P_{t-1}^{*}+\pi_{t-1}
\end{aligned}
$$

\subsection{Monetary Policy}

Since Bolivia doesn't have common policy instruments, the monetary interest rate rule, can be modeled with the Taylor Rule, taking care to consider exchange rates. This type of rule was used by Schmith - Hebbel and Tapia (2002) and Caputo et. al. (2006)

$$
r_{t}=\psi_{i} r_{t-1}+\left(1-\psi_{i}\right)\left(\psi_{\pi} \pi_{t}+\psi_{y} y_{t}+\psi_{\Delta s} \Delta s_{t}\right)+v_{t}^{m}
$$

Where $r_{t}$ is the real interest rate, that is a monetary policy tool, $\psi_{\pi}$ and $\psi_{y}$ are responses of the monetary authority to deviations of inflation and GPD growth of their natural level. $\psi_{\Delta s}$ shows response to nominal exchange rate deviations. 


\subsection{Fiscal Policy}

Government budget constraint and taxes revenues are given by:

$$
\begin{gathered}
P_{t} G_{t}=\tau_{t}^{c} P_{t} C_{t}+\tau_{t}^{N} P_{t} N_{t}+(1-\lambda) \tau_{t}^{D} D_{t}^{o}+R_{t}^{-1} B_{t+1}+S_{t}\left(\Phi\left(\frac{S_{t} B_{t}^{*}}{P_{t} Y_{t}}\right) R_{t}^{*}\right)^{-1} B_{t+1}^{G^{*}}-B_{t}-S_{t} B_{t}^{G^{*}} \\
\tau_{t}^{N, D}\left(P_{t} Y_{t}-P_{t} I_{t}+\left(P_{t}^{F}-S_{t} P_{t}^{F^{*}}\right) Y_{t}^{F}\right)
\end{gathered}
$$

\subsubsection{Fiscal Rules}

Galí et. al. (2007) proposed a fiscal rule where taxes revenues are equal to government

expenses. Let's define $g_{t}=\frac{G_{t}-G}{Y}, t_{t}=\frac{T_{t}-T}{Y}$ and bonds as $b_{t}=\frac{\left(\frac{B_{t}}{P_{t-1}}\right)-\frac{B}{P}}{Y}$. So, according to this rule, taxes adjust whenever debt or spending change.

Fiscal rules applied are generalization of García and Restrepo (2007).

$$
\tau_{t}^{c} P_{t} C_{t}+\tau_{t}\left(P_{t} Y_{t}-P_{t} I_{t}+\left(P_{t}^{F}-S_{t} P_{t}^{F^{*}}\right) Y_{t}^{F}\right)=\phi_{b} B_{t}+\phi_{g} P_{t} G_{t}
$$

Allowing $\phi_{g}=1$ and $\phi_{b}=0$, the government budget constraint is in equilibrium, and in order to hold it, taxes must adjust in every period.

$$
\tau_{t}^{c} P_{t} C_{t}+\tau_{t}\left(P_{t} Y_{t}-P_{t} I_{t}+\left(P_{t}^{F}-S_{t} P_{t}^{F^{*}}\right) Y_{t}^{F}\right)=\phi_{g} P_{t} G_{t}
$$

\subsection{Market clearing condition}

Market clearing conditions are given by:

$$
\begin{aligned}
& N_{t}=\int_{0}^{1} N_{t}(j) d j \\
& M_{t}=\int_{0}^{1} M_{t}(j) d j
\end{aligned}
$$




$$
Y_{t}=C_{t}+I_{t}+G_{t}+X N_{t}
$$

And equilibrium in the economy is given by:

$$
P_{t}\left(C_{t}+I_{t}+G_{t}\right)=P_{t} Y_{t}+P_{t}^{F} Y_{t}^{F}-S_{t} P_{t}^{F^{*}} Y_{t}^{F}+S_{t}\left(\Phi\left(\frac{S_{t} B_{t}^{*}}{P_{t} Y_{t}}\right) R_{t}^{*}\right)^{-1} B_{t+1}^{*}-S_{t} B_{t}^{*}
$$

\subsection{Closing the model}

In order to close the model we must use the following equations:

Real exchange rate

$$
R E R_{t}=\frac{S_{t} P_{t}^{F^{*}}}{P_{t}}
$$

Interest rate

$$
\text { int }_{t}=r_{t}+\pi_{t+1}
$$

Uncovered interest parity

$$
r_{t}-\pi_{t+1}=r_{t}^{*}+s_{t+1}-s_{t}
$$

\subsection{Stochastic exogenous process}

Many shocks hit the economy:

Preference shocks 


$$
\begin{aligned}
& v_{t}^{c}=\rho^{c} v_{t-1}^{c}+\varepsilon_{t}^{c} \\
& v_{t}^{N}=\rho^{N} v_{t-1}^{N}+\varepsilon_{t}^{N}
\end{aligned}
$$

Technology shock

$$
a_{t}=\rho^{a} a_{t-1}+\varepsilon_{t}^{a}
$$

Monetary shock

$$
v_{t}^{m}=\rho^{m} v_{t-1}^{m}+\varepsilon_{t}^{m}
$$

Fiscal spending shock

$$
g_{t}=\rho^{g} g_{t-1}+\varepsilon_{t}^{g}
$$

Foreign interest rate shock

$$
r_{t}^{*}=\rho^{r^{*}} r_{t-1}^{*}+\varepsilon_{t}^{r^{*}}
$$

Foreign prices shock

$$
p_{t}^{F^{*}}=\rho^{p^{F^{*}}} p_{t-1}^{F^{*}}+\varepsilon_{t}^{p^{F^{*}}}
$$

Where $\rho^{i}$ represent shocks persistence $\varepsilon_{t}^{i}$ follows a normal distribution with zero mean and variance $\sigma_{i, t}^{2}, i=v^{c}, v^{N}, a, v^{m}, g, r^{*}, p^{F^{*}}$; what's more, innovations are not correlated.

\section{Data and calibration}

We use the following series: consumption, GDP, investment, fiscal spending, net exports, tax rate, real remuneration, total population working, Bolivian real interest rate, nominal and real exchange rate, inflation, domestic and external debt; and foreign interest rate. 
Log - linearization technique requires all variables must be in $\log$ - deviations from steady state $^{6}$, so it's necessary use some steady state measure ${ }^{7}$. However, doesn't exist a theory that supports that the steady state, e.g. GDP, should be a moving average weighted, which is the HP's outcome. Consequently, all variables that are hit by shocks and they produce changes in the business cycle. Therefore, high frequency band pass filter proposed by Christiano \& Fitzgerald (1999), univaried method, that will allow us to incorporate the business cycles and isolate short or long run movements, privileging business cycles defined by the researcher.

Alternatively, we can use the Nadaraya - Watson non - parametric filter. So, if we understand seasonality as a systematic movement, no necessary regular, produced in the year, Hylleberg (1992); the problem is, how to treat it? First, there is a group of economists that believe that seasonality must be eliminated; second, another group points out that seasonality is known by economic agents and they will make their decisions according to these; consequently, it should be an error to eliminate seasonality in an economic research.

In this sense, the procedures to isolate the seasonal component are varied and depend on the specific study: a) an effortless filter which use regression with dummy variables; b)Box Jenkins (1976) difference seasonality filter; c) ARIMA X-11 and X-12 filter; d) TRAMO/SEAT filter.

Based on Bianchi (1997), we applied ARIMA X-12 which discomposes series under an additive background. Trend - cycle component can be obtained using ARIMA X-12, so we can apply a kind of filter like HP to get the cycle and trend in the long run.

Steady states of variables and calibrated parameters are listed in tables 1 and 2.

The following steady states are obtained using Nadaraya - Watson filter: C/Y, I/Y, G/Y, $\mathrm{X} / \mathrm{Y}, \mathrm{M} / \mathrm{Y}, \mathrm{G} / \mathrm{C}, \mathrm{P}^{\mathrm{f}} / \mathrm{P}, \mathrm{Y}^{\mathrm{f}} / \mathrm{Y}, \mathrm{RER}, \mathrm{N}, \mathrm{W}$, inflation and tax pressure. Country risk premium is calibrated using Corp Banca Group average qualification for Bolivia. At the same time, consumption, labor and capital taxes are being taken from Bolivia tax structure.

\footnotetext{
${ }^{6}$ In dynamic stochastic general equilibrium models, we must understand that it refers to the natural level where there is no market friction.

${ }^{7}$ Hodrick y Prescott filter is generally accepted.
} 
Hybrid New Keynesian Phillips Curve parameters are obtained from Valdivia (2008) taking care of contemporaneous pass - through similar to other papers for Bolivia, before 2005. Moreover, Taylor rule, which takes the responses of the Central Bank to variations of nominal exchange rate, is estimated by General Method of Moments (GMM). Results of the GMM procedure gave us consistency when the Central Bank is worried about exchange rate movements, in our case crawling - peg system.

Nominal interest rate calibration is based on the Central Bank of Bolivia Monetary Report (January, 2008). Besides, Bolivia population structure of Ricardian households and rule - of thumb households are taking of National Statistical Institute household's surveys. The last parameters are standard in economic literature.

\section{Fiscal spending effects}

Fiscal rules reduce exogenous shocks effect on the economy. Figure $\mathrm{N}^{\mathrm{o}} 1$, shows how fiscal shock hits the economy and how the model reacts according to the first fiscal rule. In this case, domestic debt, foreign debt, total consumption, rule - of -thumb households, ricardian households, investment, capital, nominal interest rate, labor, Tobin's Q, inflation, country risk premium, real interest rate, real exchange rate, marginal cost, tax pressure, nominal exchange rate, wages, net exports, capital price and output (GDP).

If we consider positive shocks in all exogenous variables, we can expect that variables are hit by the fiscal shock and other shocks. They generate movements that produce oscillations in impulse responses functions. For that reason, once the fiscal expenditure shock hit the economy, the model structure, with lags, allows oscillations in variables due to they are hit by other shocks.

We can observe that fiscal spending shock has positive effect over total consumption, as a consequence of agent's structure, figure $N^{0} 1$. As we expected, rule - of - thumb households reacts in a positive manner explained, $2.5 \%$, by an increase in the real interest which reduces Ricardian household's consumption, $-0.6 \%$. What's more, as output increases, $0.6 \%$, price of factors raises as well, $3 \%$ and $1.2 \%$, it is reflected in an inflation increase, $2 \%$, through the firms channel cost. In response to inflation increases, the Central Bank raises its nominal 
interest rate, $35 \mathrm{bp}$, in order to moderate investment, $-2 \%$, and reduce inflation pressures. As a consequence, this negative effect acts on Ricardian households that reduce their consumption.

The multiplier effect of fiscal spending shock is reflected in new levels of foreign debt. It increases $2 \%$, which has effects on variables taking in the model. As a consequence of increases in price of factors, labor supply increases, $1.35 \%$, explained by hand - to - mouth households. On the other hand, there is a depreciation of nominal exchange rate, $1.8 \%$, as an effect of inflation increases greater than interest rate increase. At the same time, since price increases are greater than nominal exchange rate depreciation. This turns out a weaker real exchange rate appreciation, $0.05 \%$; so net exports are affected negatively, $0.05 \%$, but over time it recovers to its natural level and is led by exchange rate movement.

Shadow price of capital, Tobin's Q, falls as a consequence of negative effect of fiscal spending shocks, $0.025 \%$. This result is consequence of increases in prices that are greater than increases in real interest rate and capital price. Moreover, country risk premium is boosted by nominal exchange rate depreciation, $1.5 \%$, and foreign debt increase is greater than output and inflation increases. Finally, since production increases, pressure tax is being pushed up by output movements, $2 \%$.

Figure $\mathrm{N}^{\mathrm{O}} 2$ shows how the model reacts to the second fiscal rule, when only taxes act, and how it helps to reduce the effect the fiscal spending shocks. In this case, since the economy is hit by a fiscal shock, it reduces the tax pressure, $1.9 \%$, in order to generate more fiscal spending, and external debt increases, 3.5\%.

Impulse-response structure is the same as the first fiscal rule, but the magnitudes are different. The most relevant results are: a) the increase of total consumption is greater than the first one; b) since the increase in factor prices is greater than the first one, marginal cost is higher and pass - through to inflation increases which are more than in the first case; c) given the increases of inflation, the Central Bank responds aggressively through increases the nominal interest rate, so investment contraction is higher than depreciation in nominal exchange rates in order to moderate imported inflation. 
Impulse response structure is the same as the first fiscal rule, but the magnitudes are different. The most relevant results are: a) the increase of total consumption is greater than the first one; b) since the increase in factor prices is greater than the first one, marginal cost is higher and pass - through to inflation increases which are more than in the first case; c) given the increases of inflation, the Central Bank responds aggressively through increases in a nominal interest rate, so the contraction in investment is higher than depreciation in nominal exchange rates in order to moderate imported inflation.

Finally, in the case of Bolivia we need to know, which of the two fiscal rules have more stabilizing effects against a fiscal spending shock? In figure $\mathrm{N}^{\mathrm{o}} 3$, we compare results obtained above with a canonical model that doesn't have a fiscal rule.

In all obtained outcomes above, the first fiscal rule, where taxes respond to the new external debt in order to generate more fiscal spending, has more stabilizing effects. In particular, the effect of fiscal spending shock on inflation is moderated around $50 \%$ of the total effect. The effect of fiscal shock without rule is $0.45 \%$ on the inflation, and applying the rule reduces it to $0.21 \%$. This outcome can be seen comparing the canonical model when it doesn't have a fiscal rule with the one that has it.

In all outcomes obtained above, the first fiscal rule, (where taxes respond to the new external debt in order to generate more fiscal spending), has more stabilizing effects. In particular, the effect of fiscal spending shock on inflation is moderated around $50 \%$ of the total effect. The effect of fiscal shock without rule is $0.45 \%$ on the inflation, and applying the rule reduces it to $0.21 \%$. This outcome can be seen comparing the canonical model when it doesn't have a fiscal rule with the one that has it.

Despite of the fiscal shock effect on output is sacrificed, and all variables which are influenced by it. In terms of welfare, the outcome obtained above is preferable cause of negative inflation effects is reduced on consumption. 


\section{Conclusions and future research}

We developed a canonical model according to new macroeconomic vintage called new Keynesian models with imperfect competition in the determinacy inflation.

Based on dynamic stochastic general equilibrium model, we looked for compare the fundamentals performance when they are hit by fiscal spending shock. We used two types of fiscal rules: first, taxes adjust according to debt level and government spending, therefore debt plays a central role; second, a budget balanced - zero debt - where taxes adjust every time in order to keep equilibrium.

Consequently, after computing and simulating our three models, two of them with different fiscal rules and one with any fiscal rule, our results can be summarized as follows: a) an increase in total cost of factors, e.g. prices, and an increase in consumption of rule - of thumb households; b) since marginal cost increased, through HNKPC, inflation raises more than expected, and Central Bank must react through raising the monetary policy interest rate leading investment to diminish in the short run, so as to reduce inflation pressures; c) there is a nominal exchange rate depreciation and little real exchange rate appreciation; d) exports are guided by real exchange rate, and finally; e) country risk premium raises.

Finally, the most important result is how the first fiscal rule, has more stabilizing effects over the fundamentals and overall in the model than the second one, when we consider a budget balanced getting zero debt level. What's more, inflation reduces around $50 \%$ as a consequence of fiscal shock

Future research in this type of models applying fiscal rules should consider: a) not only an open economy Phillips Curve which takes into account inflation imported, but also acquire total prices aggregation and modeling two Phillips curves in order to clarify the inflation imported channel; b) a structural fiscal surplus effects and its effects against exogenous shocks,

c) not only a calibrated model, but also compute using Bayesian econometric techniques so as to improve estimations and forecasting about fundamentals. 


\section{Bibliography}

Andrés, J. and R. Domenéch (2005): “Automatic Stabilizers, Fiscal Rules and Macroecomomic Stability", Valencia University.

Central Bank of Bolivia: Monetary Policy Report, January, 2008.

Bénassy, J-P. (2002), The Macroeconomics of Imperfect Competition and Nonclearing Markets, MIT Press.

Blanchard, O. and R. Perotti (2002). "An Empirical Characterization of the Dynamic Effects of Changes in Government Spending and Taxes on Output." Quarterly Journal of Economics, No117, pg 1329-1368.

Caputo, R., Liendo, F and J.P. Medina (2006): "New Keynesian Models for Chile in the Inflation - Targeting Period: A Structural Investigation”, Central Bank of Chine, WP 402.

Fatás, A. and I. Mihov (2001). "The Effects of Fiscal Policy on Consumption and Employment: Theory and Evidence." INSEAD, Working Paper.

Favero, C. (2001): Applied Macroeconomitrics, Oxford University Press.

Galí, J. and M. Echeinbaum (2004): "Monetary Policy and Exchange Rate Volatility in a Small Open Economy", Review of Economic Studies. No 72, pg 707 - 734.

Galí, J., López - Salido, D. and J. Vallés (2007): "Understanding the Effects of Government Spending on Consumption", European Economic Association, Vol 5, No 1, pgh 227 - 270.

Galí, J. and M. Gertler (1999): "Inflation dynamics: a structural econometric approach" Journal of Monetary Economics, Vol. 44, № 2, pg. 195-222. 
García, C. and J. Restrepo (2006): “The Case of Countercyclical Rule - Based Fiscal Regime”, Central Bank of Chile.

García, C. and J. Restrepo (2007): "How Effective is Government Spending in a Small Open Economy with Distortionary Taxes", Central Bank of Chile.

López- Salido D. and R. Blakrishnan (2002): "Understanding UK inflation: the role of openness" Bank of England, WP 164.

Schmidt-Hebbel, K. and M. Tapia (2002): "Inflation Targeting in Chile", North American Journal of Economics and Finance $N^{\circ} 13$, pg $125-146$.

Smets, F. and R. Wouters (2002): "An Estimated Stochastic Dynamic General Equilibrium Model of the Euro Area", European Central Bank.

Valdivia, D. (2008): “¿Es importante la fijación de precios para entender la dinámica de la inflación en Bolivia?”, INESAD, WP Nº2/2008. 


\section{Table $\mathbf{N}^{\mathbf{o}} 1$}

\section{Steady States}

$\begin{array}{lr}\mathrm{C} / \mathrm{Y} & 0.74 \\ \mathrm{I} / \mathrm{Y} & 0.15 \\ \mathrm{G} / \mathrm{Y} & 0.12 \\ \mathrm{X} / \mathrm{Y} & 0.27 \\ \mathrm{Pf} / \mathrm{P} & 0.0052 \\ \mathrm{Yf} / \mathrm{Y} & 1.32 \\ \mathrm{RER} & 98.73 \\ \mathrm{M} / \mathrm{Y} & 0.29 \\ \mathrm{tau} / \mathrm{C} & 0.40 \\ \mathrm{~b} / \mathrm{C} & 0.65 \\ \mathrm{G} / \mathrm{C} & 0.15 \\ \text { tau/Y } & 0.14 \\ \text { Country risk } & 5\end{array}$

\section{Table $\mathbf{N}^{\circ} 2$}

\section{Basic Parameters}

$\sigma$ Risk aversion coefficient 2

$\tau^{c}$ consumption tax rate $\quad 20 \%$

$\tau^{\mathrm{n}}$ Labor tax rate $\quad 13 \%$

$\tau^{\mathrm{k}}$ Capital tax rate $\quad 40 \%$

$\lambda$ Weight of rule - of - thumb households $\quad 0.7$

$\varphi$ Marginal elasticity of labor disutility 1.7

$v^{c}$ Consumption idiosyncratic shock in ss 1

$v^{\mathrm{n}}$ Labor idiosyncratic shock in ss 1

$\delta$ Depreciation rate $\quad 0.25$

$\eta$ Investment elasticity to Q 1

$\Pi$ Inflation in ss $\quad 6.01$

$\eta^{\mathrm{x}}$ RER elasticity exports 1

$\alpha$ Capital share in CES production function $\quad 0.6$

$\xi^{\mathrm{f}} \mathrm{HNKPC}$ forward parameter $\quad 0.4966$

$\xi^{\mathrm{b}}$ HNKPC backward parameter $\quad 0.4581$

$\lambda_{\pi}$ HNKPC marginal cost parameter $\quad 0.4852$

$\chi_{\mathrm{mc}}$ HNKPC foreign pass-through $\quad 0.4278$

$\sigma_{\mathrm{s}}$ CES Substitution elasticity 2

$\psi_{\mathrm{i}}$ Taylor rule inertial interest rate component $\quad 0.96$

$\psi_{\pi}$ Taylor rule inflation component $\quad 1.25$

$\psi_{\mathrm{y}}$ Taylor rule output component $\quad 6.9070$

$\psi_{\mathrm{s}}$ Taylor rule nominal exchange rate variation comp -14.95

$\mathrm{R}^{*}$ Foreign interest rate $\quad 4.43 \%$ 
Figure $N^{\circ} 1$

\section{Fiscal Shock Impulse Responses}

\section{Rule 1}
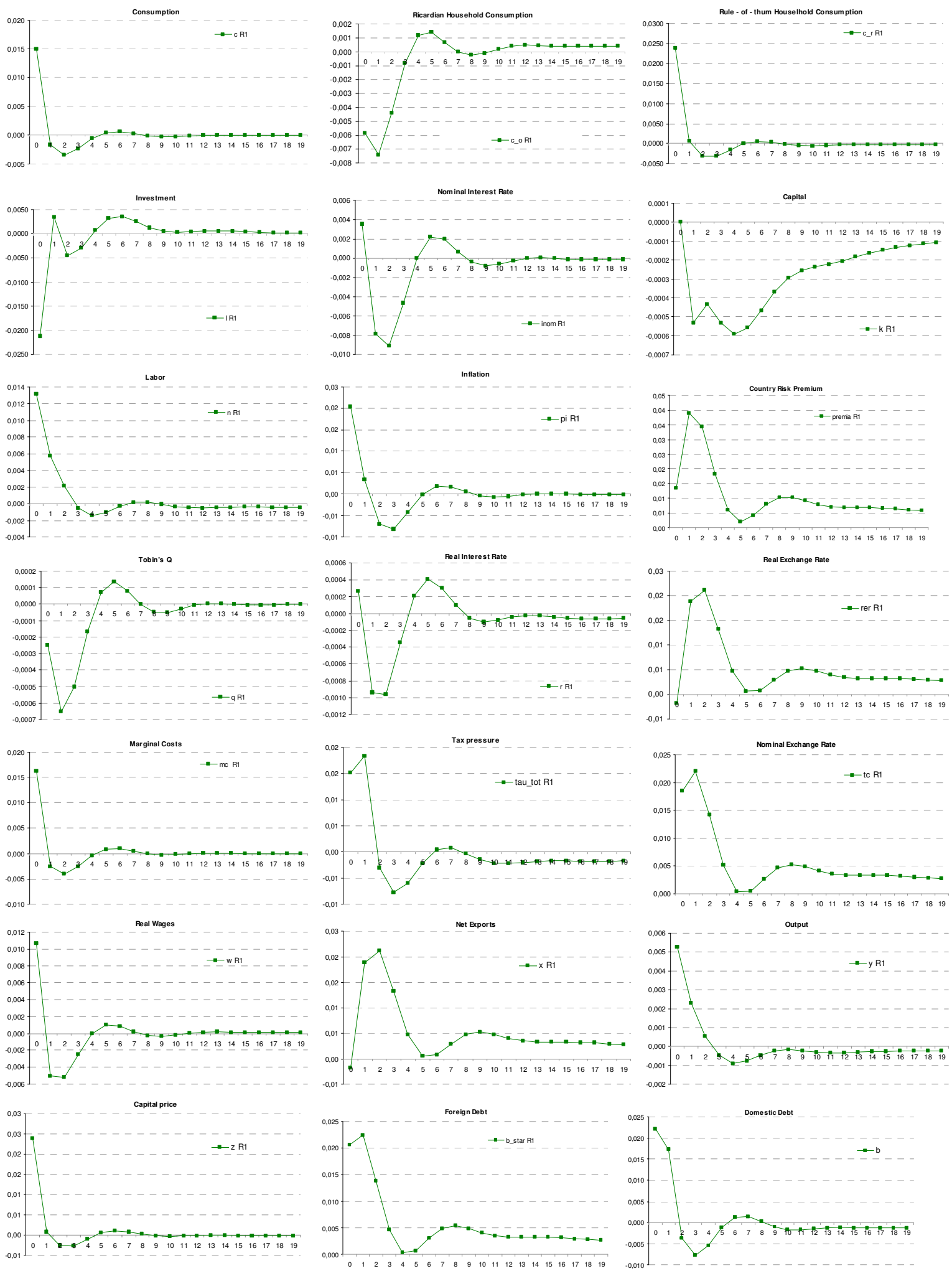
Figure $\mathbf{N}^{\mathbf{0}} 2$

\section{Fiscal Shock Impulse Responses}

\section{Rule 2}
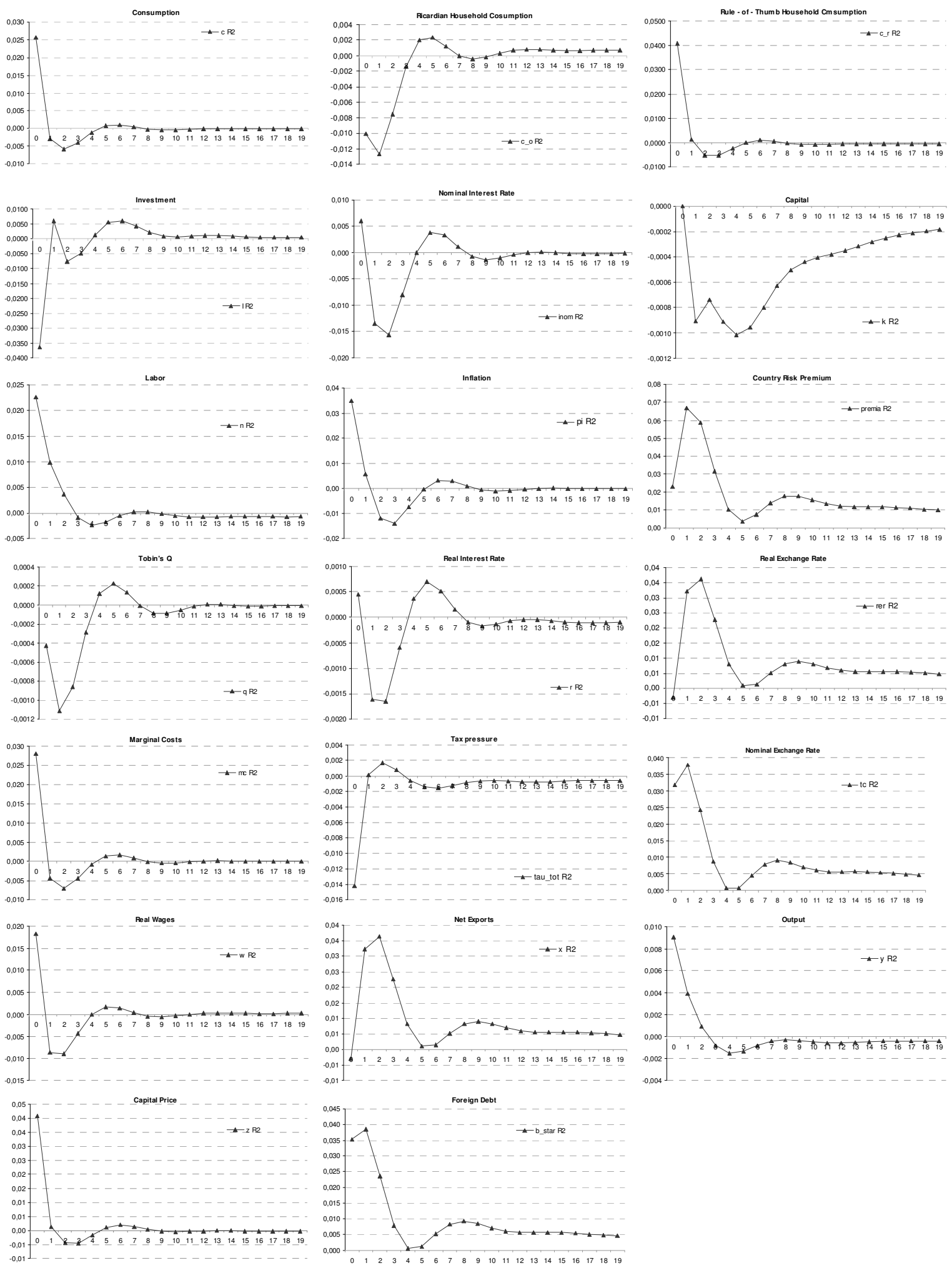
Figure $\mathbf{N}^{\circ} 3$

Fiscal shock evaluation of impulse responses

Rules 1, 2 and canonical model that doesn't have any rules
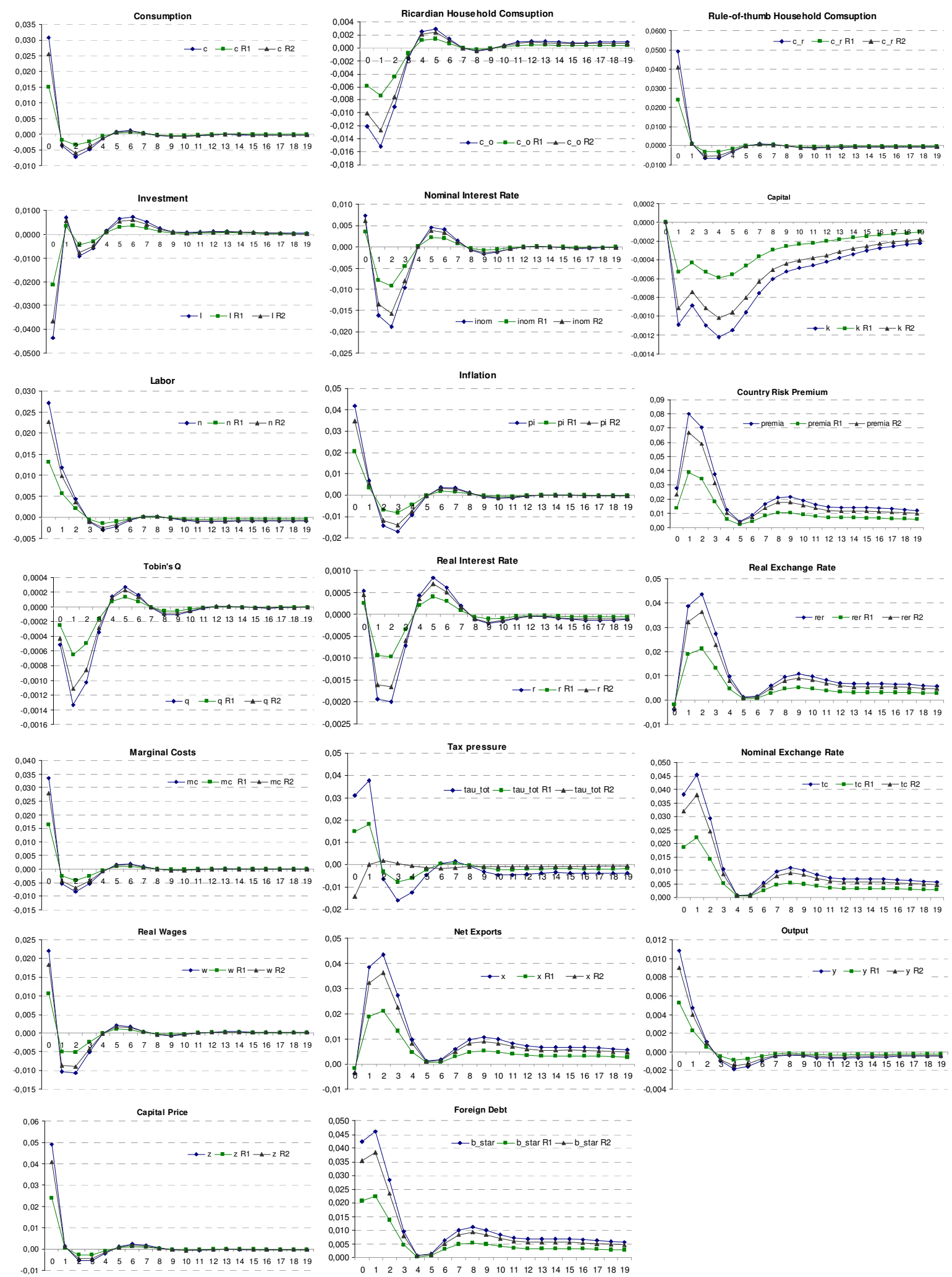

$\mathrm{R} 1$ rule $1, \mathrm{R} 2$ rule 2 and " $\mathrm{C}$ " represent the canonical model without rule 


\section{Appendix A}

\section{Log - linearized Model}

Log- linearized model solution around the steady state is:

Ricardian and rule-of-thumb households:

$$
\begin{aligned}
& c_{t}^{o}=c_{t+1}^{o}-\frac{1}{\sigma}\left[r_{t}-\hat{\pi}_{t+1}+v_{t+1}^{c}-v_{t}^{c}-\left(\frac{\tau^{c}}{1+\tau^{c}}\right) \Delta \hat{\tau}_{t+1}^{c}\right] \\
& c_{t}^{r}=w_{t}-n_{t}-\left(\frac{\tau^{N}}{1-\tau^{N}}\right) \hat{\tau}_{t}^{N}-\left(\frac{\tau^{c}}{1+\tau^{c}}\right) \hat{\tau}_{t}^{c}
\end{aligned}
$$

Aggregation of consumption:

$$
c_{t}=\lambda c_{t}^{r}+(1-\lambda) c_{t}^{o}
$$

Labor supply:

$$
w_{t}=\left(\frac{\tau^{N}}{1-\tau^{N}}\right) \hat{\tau}_{t}^{N}+\left(\frac{\tau^{c}}{1-\tau^{N}}\right) \frac{N^{\varphi} C^{o} \sigma}{W v^{c} / v^{N}} \hat{\tau}_{t}^{c}+v_{t}^{N}-v_{t}^{c}+\varphi n_{t}+\sigma c_{t}^{o}
$$

Interest rate and investment return are given by:

$$
\begin{aligned}
r_{t}= & \left(\frac{R+\delta}{1+R}\right) Z_{t+1} \\
q_{t}= & \left(\frac{1-\delta}{1+R}+\left(\frac{\eta-1}{1+R}\right) \delta \Pi\right) q_{t+1}+\left(1-\tau^{k}\right)\left(\frac{R+\delta}{1+R}\right) \Pi Z_{t+1}-\left(\frac{R+\delta}{1+R}\right) \Pi \tau^{k} \hat{\tau}_{t+1}^{k} \\
& -\left(\left(1-\tau^{k}\right)\left(\frac{R+\delta}{1+R}\right)+\left(\frac{1-\delta}{1+R}\right)\right) \Pi\left(r_{t}-\hat{\pi}_{t+1}\right)
\end{aligned}
$$


Capital law of movement:

$$
k_{t+1}=(1-\delta) k_{t}+\delta i_{t}
$$

Equilibrium:

$$
y_{t}=\frac{C}{Y} c_{t}+\frac{I}{Y} i_{t}+\frac{G}{Y} g_{t}+\frac{X}{Y} x_{t}
$$

Labor, investment, capital and debt aggregation are given by:

$$
\begin{aligned}
& n_{t}=\lambda n_{t}^{r}+(1-\lambda) n_{t}^{o} \\
& i_{t}=i_{t}^{o} \\
& k_{t}=k_{t}^{o} \\
& b_{t}=(1-\lambda) b_{t}^{o} \\
& b_{t}^{*}=b_{t}^{G^{*}}+(1-\lambda) b_{t}^{o^{*}}
\end{aligned}
$$

The economy constraint:

$$
\begin{aligned}
\Phi b_{t}^{*} & =\frac{1}{R^{*}} b_{t+1}^{*}+y_{t}-\frac{C}{Y} c_{t}-\frac{I}{Y} i_{t}-\frac{G}{Y} g_{t}+\frac{P^{F}}{P} \frac{Y^{F}}{Y} p_{t}^{F}+\left(\frac{P^{F}}{P}-R E R\right) \frac{Y^{F}}{Y} y_{t}^{F} \\
& -R E R \frac{Y^{F}}{Y} \operatorname{rer}_{t}-\left(\frac{P^{F}}{P} \frac{Y^{F}}{Y}+\left(\frac{1}{R^{*}}-\Phi\right)\right) p_{t}+\left(\frac{1}{R^{*}}-\Phi\right) s_{t}-\frac{1}{R^{*}} \hat{\phi}_{t}
\end{aligned}
$$

Country risk premium:

$$
\hat{\phi}_{t}=s_{t}-p_{t}+b_{t}^{*}-y_{t}
$$

Foreign production function

$$
y_{t}^{F}=\rho^{y f} y_{t-1}^{F}+\varepsilon_{t}^{y f}
$$

Net Exports:

$$
x_{t}=\eta^{x} \operatorname{rer}_{t}+c_{t}^{*}
$$


Real Exchange rate:

$$
\operatorname{rer}_{t}=s_{t}+p_{t}^{F^{*}}-p_{t}
$$

Labor and consumption shocks:

$$
\begin{aligned}
& v_{t}^{c}=\rho^{c} v_{t-1}^{c}+\varepsilon_{t}^{c} \\
& v_{t}^{N}=\rho^{N} v_{t-1}^{N}+\varepsilon_{t}^{N}
\end{aligned}
$$

Technological shock

$$
a_{t}=\rho^{a} a_{t-1}+\varepsilon_{t}^{a}
$$

Monetary shock

$$
v_{t}^{m}=\rho^{m} v_{t-1}^{m}+\varepsilon_{t}^{m}
$$

Fiscal shock

$$
g_{t}=\rho^{g} g_{t-1}+\varepsilon_{t}^{g}
$$

Foreign interest rate shock

$$
r_{t}^{*}=\rho^{r^{*}} r_{t-1}^{*}+\varepsilon_{t}^{r^{*}}
$$

Foreign prices shock

$$
p_{t}^{F^{*}}=\rho^{p^{F^{*}}} p_{t-1}^{F^{*}}+\varepsilon_{t}^{p^{F^{*}}}
$$

Taxes shock

$$
\begin{aligned}
& \tau_{t}^{c}=\rho^{\tau^{c}} \tau_{t-1}^{c}+\mathcal{E}_{t}^{\tau^{c}} \\
& \tau_{t}^{k}=\rho^{\tau^{k}} \tau_{t-1}^{k}+\mathcal{E}_{t}^{\tau^{k}} \\
& \tau_{t}^{N}=\rho^{\tau^{N}} \tau_{t-1}^{N}+\mathcal{E}_{t}^{\tau^{N}}
\end{aligned}
$$

Firm's decisions

$$
n_{t}-m_{t}=p_{t}^{m}-w_{t}
$$

Production function is given by

$$
y_{t}=a_{t}+\alpha m_{t}+(1-\alpha) n_{t}
$$


The Hybrid New Keynesian Phillips Curve

$$
\pi_{t}=\xi^{f} \pi_{t+1}+\xi^{b} \pi_{t-1}+\lambda_{\pi} m c_{t}+\rho\left(p_{t}^{F^{*}}+S_{t}+w_{t}\right)
$$

Marginal Costs are given by

$$
m c_{t}=\left(1-\chi_{m c}\right)\left(\sigma_{s}-1\right) w_{t}+\chi_{m c}\left(\sigma_{s}-1\right) p_{t}^{m}-a_{t}
$$

Monetary policy rule

$$
r_{t}=\psi_{i} r_{t-1}+\left(1-\psi_{i}\right)\left(\psi_{\pi} \pi_{t}+\psi_{y} y_{t}+\psi_{\Delta s} \Delta s_{t}\right)+v_{t}^{m}
$$

Fisher's equation

$$
\operatorname{int}_{t}=r_{t}+\pi_{t+1}
$$

Uncovered interest parity

$$
r_{t}-\pi_{t+1}=r_{t}^{*}+s_{t+1}-s_{t}
$$

Fiscal Rule 1

$$
\begin{aligned}
& \tau^{c}\left(\hat{\tau}_{t}^{c}+c_{t}\right) \frac{\tau}{C} \hat{\tau}_{t}=\phi_{b} \frac{b}{C} b_{t}+\phi_{g} \frac{G}{C} g_{t} \\
& \frac{\tau}{Y} \hat{\tau}_{t}=y_{t}+\frac{I}{Y} i_{t}+\frac{P^{F}}{P} \frac{Y^{F}}{Y}\left(p_{t}^{F}-p_{t}+y_{t}^{F}\right)-R E R \frac{Y^{F}}{Y}\left(\operatorname{rer}_{t}+y_{t}^{F}\right)
\end{aligned}
$$

Fiscal Rule 2

$$
\tau^{c}\left(\hat{\tau}_{t}^{c}+c_{t}\right) \frac{\tau}{C} \hat{\tau}_{t}=\phi_{g} \frac{G}{C} g_{t}
$$

